\title{
CULTURA Y CRISIS EN EL \\ CAPITALISMO AVANZADO. ACOTACIONES EN TORNO A \\ DANIEL BELL
}

Jaime Nicolás Muñiz

1. Haciendo gala de una gallardía rayana en la insolencia, la sociedad occidental - libre, opulenta, del bienestar - ha cumplido su curso histórico en los dos últimos siglos bajo el estandarte de lo fáustico, de la fe ilimitada en sus propias capacidades de adaptación, transformación y progreso. Inevitablemente, esta idea del progreso se ha convertido incluso en uno de los pilares básicos de la ideología legitimadora de la llamada -imprecisamente, pues ni siquiera la geografía es inequívoca al respecto- sociedad occidental.

Pero ya la misma insistente proclamación de Fausto pone de manifiesto lo filisteo, no tan gallardo, de la fe en el progreso. La sociedad capitalista -competitiva por propia definición- ha vivido siempre apoderada de una sensación casi apocalíptica, experimentando una atormentada preocupación por su continuidad. La idea, mejor: la ideología, comenzó, empero, a contradecir a la realidad no apenas apagado por completo el optimista espíritu de la Ilustración: el impetuoso desarrollo de la revolución industrial desvelaba elocuentemente las otras caras del progreso. Las ascendentes luchas de clases amenazaban también, desde un flanco paralelo, la integridad del orden social burgués, y para defender su tibia, débil identidad, la burguesía no vacilaría en llegar incluso a negarse a sí misma, suspendiendo cuando fue necesario, como en el fascismo, la vigencia de sacrosantos principios de su universalista moral pública. La consagración del progreso se manifestaba así como un ar- 
did para la conjura de su propia negación, como un mecanismo colectivo de refuerzo de la «falsa conciencia» de la burguesía.

Sin negar la dinámica esencial del capitalismo -elevándola, por el contrario, a la condición de categoría determinante en términos sólo comparables a los que bajo la fórmula de la imposibilidad lógica de un capitalismo estancado propugnara un pensador de signo tan contrario, pero pesimista en el fondo respecto al futuro del capitalismo, como Joseph A. Schumpeter-, sin necesidad, pues, de negar su movimiento, Marx sólo tuvo que cuestionar la meta final y la linearidad del desarrollo capitalista. El progreso del capitalismo, acompañado inextricablemente de destrucción y despilfarro, implicaba, en aras del triunfo de la razón histórica, la necesidad -lógica también- de su Selbstaufbebung.

$\mathrm{Y}$ si en Marx la desaparición del capitalismo, aún asistida paralelamente de fenómenos de crisis (Zusammenbrucb) en dosis tales que cuestionarían la idea de progreso, conducía dialécticamente a la instauración de un nuevo orden social, Nietzsche contemplaba el fin del universo burgués, que inevitablemente habría de producirse como colofón de las ingentes fuerzas materiales y espirituales liberadas por la propia burguesía, no como superación, sino como destrucción, como la instauración de anarquía y desorden, fenómenos que atisbaba en la difusión de un ethos nihilista en la cultura y el arte de su tiempo. Tal fue, por lo demás, la tarea a la que, en un apasionado esfruarzo por contribuir a la realización de su propia profecía, dedicaría Nietzsche lo más granado de su obra.

En las postrimerías del mismo siglo $\mathrm{xx}$ nada ha aplacado la tensión entre lo prometeico y lo apocalíptico en el seno del capitalismo. Por el contrario, a medida que la sociedad capitalista ha ido consumiendo sus pasos, se ha ido desvelando, cada vez más abiertamente, el impulso destructor que en sus entrañas anida —un impulso que amenaza no sólo la integridad y la persistencia misma del entorno físico, sino que también se extiende por igual, deshumanizadoramente, a la propia naturaleza interior del individuo y la sociedad.

Rindiéndose ante esta evidencia, bajo el circunloquio -muy expresivo, por lo demás - de las contradicciones culturales del capitalismo, en su última obra se enfrenta Bell (1) con el tema del fin de la sociedad capitalista. Apocalíptico por cuanto no prevé una salida natural para la crisis que diagnostica; profundamente nietzscheano; y antimarxiano, como no trata de ocultar, sus apasionantes reflexiones acerca de la autonomización de la cultura frente a la base económica y el carácter deletéreo de la racionalidad tecnológica se

(1) Daniel BeLL: The Cultural Contradictions of Capitalism, Basic Books, Nueva York, 1976. Existe una muy cuidada traducción castellana de Néstor A. Míguez, recientemente publicada en Alianza Editorial, Madrid, 1977, bajo el título de Las contradicciones culturales del capitalismo. Los números entre paréntesis en las citas y en el texto corresponden a esta versión castellana de la obra de Bell. 
engarzan muy estrechamente con los también pesimistas análisis de la escuela de Frankfurt, y no sólo con la tesis de la dialéctica de la ilustración ( $\mathrm{y}$, en cierta medida, con la de la sociedad unidimensional), sino también con los planteamientos que en torno a la sociedad del capitalismo tardío formula Jürgen Habermas, indudablemente el máximo representante contemporáneo -en unión de Herbert Marcuse- de la tradición crítica de Horkheimer y Adorno (2).

2. Por lo demás, hablar de las contradicciones culturales del capitalismo puede parecer en franca discordancia con las tesis que, no menos apodícticamente, se expresaban en los títulos de las anteriores opera magna de Daniel Bell (3). Pues, en efecto, mal se compagina la idea de crisis cultural con el diagnóstico previo del fin de la ideología, y mal casan también los conceptos de capitalismo y sociedad (post-)industrial, piezas centrales ambos de paradigmas normativos de signo contrapuesto.

En lo que atañe a la tesis del fin de la ideología, Bell es consciente de que cabría interpretarla como enteramente revisada por la idea de crisis cultural, por lo que, con la idea de salir al paso de esta objeción, se plantea expresamente la cuestión de la existencia de otras fuentes de conflicto cultural distintas del conflicto ideológico y más profundas que éste. Pese a la justeza, en líneas generales, de su análisis, Bell se ve forzado a una interpretación particular del concepto de cultura, a la que aludiremos más abajo, cuando lo más productivo habría sido, sin duda, aprovechar la ocasión para proceder a una revisión de la vieja tesis, no tan afortunada como algunos epifenómenos parecen señalar.

En cuanto a la incongruencia que se derivaría de la utilización del concepto de capitalismo después de haber teorizado acerca del advenimiento de la sociedad industrial, no habría tal si Bell hubiera llevado a sus últimas consecuencias la adopción del paradigma contrario. Pues si bien se sirve precisamente del concepto de capitalismo para subrayar la insuficiencia de definiciones, como las de la sociedad industrial y otras del mismo estilo, que sólo captan una de las dimensiones del fenómeno, concretamente: sus aspectos tecno-económicos - un criterio que, absolutizado, puede dar lugar, como

(2) La influencia de Habermas en el mundo anglosajón se percibe también en otros importantes pensadores procedentes de tradiciones no marxistas. Vid. al respecto Tom Botromore: La sociología marxista, Alianza Editorial, Madrid, 1976, y, más explícitamente, Alvin W. Gouldnen: The Dialectic of Ideology and Technology: The Origins, Grammar, and Future of Ideology, Seabury Press, Nueva York, 1976. Vid. también Anthony GIDDENs, "Habermas's critique of hermeneutics", en id., Studies in Social and Political Theory, Hutchinson, Londres, 1977 (págs. 135-164).

(3) The End of Ideology, The Free Press, Glencoe, III., 1960 (trad. castellana bajo el título El fin de las ideologías, Tecnos, Madrid, 1964), y The Coming of Post-Industrial Society, Basic Books, Nueva York, 1973 (trad. castellana en Alianza Editorial, Madrid, 1976, bajo el título El advenimiento de la sociedad postindustrial). 
así acontece, a un uso normativo del paradigma-, en la práctica todo parece indicar que Bell pierde de vista esta perspectiva, tratando de hacer extensiva, sin mayor mediación, obsesivamente, su crítica de la sociedad capitalista (occidental) a todas las sociedades avanzadas, volviendo a equiparar de hecho los conceptos de capitalismo y sociedad industrial.

Pero más grave que esa trasposición de la crítica lo es la circunstancia, que Bell parece no plantearse, de que la técnica - la instancia «neutra» pretendidamente rectora de las sociedades contemporáneas- es, ella misma, causante directa de muchos de los desequilibrios y problemas básicos de esas sociedades. De modo inexplicable, Bell se vuelve a eximir de un examen de la naturaleza y los condicionamientos sociales de la técnica en la línea, cuando menos, de la tesis de la ciencia y la técnica como «ideología» (Marcuse [4], Habermas [5]), corolario casi obligado de la idea de dialéctica de la ilustración, tan afín a sus propios planteamientos.

3. El punto nodal de las reflexiones de Daniel Bell lo constituye una crítica de las concepciones holísticas de la sociedad que incluye, desde luego, a Marx, pero también al propio Weber. La sociedad no puede entenderse, según Bell, como un todo sometido a un único principio de organización social, sino que integra un conjunto (des)articulado - «una difícil amalgama»- de órdenes guiados cada uno por su propio principio:

"La sociedad, diría yo, no es integradora, sino separadora; los diferentes ámbitos responden a diferentes normas, tienen distintos ritmos de cambio y están regulados por principios axiales diferentes y hasta contrapuestos» (23).

«Estos ámbitos no son congruentes entre sí y tienen diferentes ritmos de cambio; siguen normas diferentes que legitiman tipos de conducta diferentes y hasta opuestos» (ibid.).

Cualesquiera que sean esos ámbitos u órdenes, es obvio que la hipótesis de la disyunción - central en el planteamiento de Bcll- se halla potencialmente implicada en la idea previa de la disolución del concepto de sociedad, razón ésta por la que no puede considerarse todavía suficientemente explicativa. Optar por la disolución -a todas luces más que analítica, pese a las afirmaciones de Bell en sentido contrario- de la sociedad significa aceptar la posibilidad y la necesidad de la disyunción de los órdenes que la componen. Pero aún en el caso de que se pudiera sostener en lo esencial la crítica de Bell a las concepciones holísticas, quedaría sin explicar por qué la lógica que guía a cada uno de los órdenes es una lógica absoluta, por qué razón ha

(4) "Industrialización y capitalismo en la obra de Max Weber", en la colección de ensayos del mismo autor Etica de la revolución, Taurus, Madrid, 1969, págs. $117-140$.

(5) Vid. en J. Habermas: Wissenschaft und Technik als "Ideologie", Suhrkamp, Frankfurt a. M., 1968, el ensayo del mismo título (págs. 48-103). 
de implicar también forzosamente autonomía (6). Bell incurre aquí en un círculo vicioso: la única explicación que brinda para la disyunción es la de la falta de un principio unificante, y esto es precisamente lo que se debía demostrar. La riqueza de los pensamientos que Bell vierte en esta obra hace, en cualquier caso, olvidar esta insuficiencia inicial, y permite, fuerza incluso, un mayor enfrentamiento con sus planteamientos.

Lo importante para Bell es, como ya hemos apuntado, el desarrollo independiente de los distintos órdenes de la sociedad (el orden tecno-económico o sociedad en sentido estricto; la cultura; y el orden político o polity) y el carácter contradictorio de los principios axiales que respectivamente les guían (la racionalidad funcional, racionalidad sistémica, en el orden de la estructura social; la autorrealización del individuo, en el orden cultural, y la legitimidad, en el orden político). Pese a que Bell evita la tediosa jerga de los sistemas y los subsistemas —arbitrarios, relativos y, por ende, infinitos-, su clasificación sigue siendo igual de arbitraria, aunque menos relativa desde el momento en que acierta a escapar de la espiral taxonómica. En el seno de la trama así trazada, Bell cree poder

«discernir las fuentes estructurales de las tensiones en la sociedad: entre una estructura social (principalmente tecno-económica) que es burocrática y jerárquica, $\mathrm{y}$ un orden político que cree, formalmente, en la igualdad y la participación; entre una estructura social que está organizada fundamentalmente en base a roles y a la especialización, y una cultura que se interesa por el reforzamiento y la realización del yo y de la persona total» (26).

De ambos focos de conflicto o tensión, indudablemente son las contradicciones (7) culturales las que más interés presentan para Bell. Que el orden cultural y el tecno-económico siguen su propio y divergente desarrollo lo demuestra la circunstancia de que mientras el cambio en el orden tecnoeconómico es lineal (existe, pues, un criterio objetivo para decidir acerca del sentido del progreso en su seno),

«en la cultura siempre hay un ricorso... Boulez no reemplaza a Bach. La nueva música, la nueva pintura o la nueva poesía entran a formar parte de un repertorio ampliado de la humanidad, un depósito permanente al que los individuos pueden recurrir, en forma renovable, para remodelar su propia estética» (26);

«a diferencia de las economías o las tecnologías anticuadas, (las ideologías) no desaparecen. Estos "momentos de conciencia", como los lla-

(6) Richard LöwenthaL: "Kapitalistische Dynamik und westliche Werte", en Neue Rundschau, 1/1977, págs. 15-26, aquí 23.

(7) Para una crítica de la ligereza con que Bell emplea el término "contradicción", vid. Claus OrFE: "Postindustrielle Gesellschaft - ein politisches Program? Zu Daniel Bells Analysen", en Merkur, 9/1976, págs. 878-884. 
maba Hegel, son renovables; pueden ser revividos y reformulados a lo largo de toda la historia de una civilización. Así, una ideología roída, gastada, discutida, disecada y reformulada por un ejército de ensayistas, moralistas e intelectuales se convierte en una fuerza autónoma» (69).

El desacuerdo entre ambos órdenes, la economía y la cultura, ha acompañado desde siempre a la sociedad burguesa. Pero durante algún tiempo, mientras duraron las restricciones de la ética protestante, pudo mantenerse lo que Bell denomina «paradoja extraordinaria» del desarrollo del capitalismo, el hecho de que cada impulso (el cultural y el económico) adquiriera

«aguda conciencia del otro, lo temiera y tratara de destruirlo. Radical en economía, la burguesía se hizo conservadora en moral y en gustos culturales» (29).

Tal paradoja, sin embargo, no podia prolongarse indefinidamente. En este sentido, Bell constata un desarrollo cada vez más acelerado de la incompatibilidad de los valores técnicos y económicos de la sociedad burguesa con sus propras creaciones culturales. La ideología burguesa fue entrando en colisión con sus premisas estructurales. Pero no era sólo una dialéctica de la ilustración, una destrucción de los supuestos culturales de la burguesía por obra y gracia de la desatada racionalidad tecnológica, la que entra en juego. Es también la cultura por sí misma, la continuación del impulso cultural burgués, cuya culminación se alcanza en el modernismo, la que se va desprendiendo de las limitaciones que le imponen la técnica y la economía. Los principios puritanos y protestantes saltan en pedazos una vez que el desarrollo económico y tecnológico multiplican la capacidad de acumulación de capital y generan excedentes para el lujo, esto es: cuando los deseos ocupan el lugar de las necesidades como criterios económicos. Y la cultura, a su vez, deja de encontrar acomodo a los principios de la economía y de la sociedad: el hedonismo, versión moral del modernismo, hace imposible cualquier intento de articulación, con las consiguientes dificultades para legitimar un orden - la sociedad - que a estas alturas ha abandonado el intercambio como principio autorregulador y autolegitimador (Offe, Habermas). Pero antes de entrar más a fondo en este desplazamiento, al que también Bell concede una importancia primordial, quizá sea oportuno precisar los términos en que Bell formula la quiebra de la articulación de la cultura a las necesidades de la sociedad capitalista, así como su alcance.

El énfasis que Bell pone en la función crítica del arte patentiza la reducción del concepto de cultura. Por tal se entiende, en lo esencial, la esfera del simbolismo expresivo, de las formas simbólicas, despreocupándose de los componentes cognoscitivos, constituyentes por igual del orden cultural. Es así en la esfera de las artes, no en la de las ideologías, donde se enciende y desata la disyunción de la cultura frente al conjunto de la sociedad burguesa. Compartiendo una idea estética que, con una intención contextual 
algo distinta, también formulan Benjamin, Marcuse y el propio Habermas (8), Bell interpreta al arte como la avanzadilla en la destrucción de los mitos burgueses. La estética clásica había cumplido una función ideológica muy similar a la de la religión, creando una distancia entre la vida y los contenidos que en una y otra se reflejan, suspendiendo en la contemplación -artŕstica o religiosa- - la realización de deseos y necesidades. El arte, como la religión, consagraba esferas de la vida social no sujetas a cuestionamiento alguno. Frente a ello, la estética moderna, más bien una antiestética, universaliza el arte y cancela su distancia frente a la vida, rompe con los cánones de la estética clásica y acomete en el campo de la cultura una profanación que encuentra su paralelo en los procesos de secularización de la conciencia religiosa por obra de la ciencia moderna (161). Abundando en este paralelismo, las reflexiones de Bell en torno al declinar de la religión pueden extenderse - como así hace el mismo Bell- con respecto a la cultura y su «decadencia». También el declinar de la cultura implica, como el de la religión, la desaparición de la divisoria entre lo sagrado y lo profano - una distinción imprescindible para la reducción de complejidad social, la absorción de inseguridad y el mantenimiento de un mínimo de cohesión en el seno de la sociedad; a partir de esta premisa, Bell puede expresarse en los términos siguientes:

«Decir, pues, que "Dios ha muerto" (o, lo que sería igual: la cultura ha muerto; J. N. M.) es, en efecto, decir que los vínculos sociales se han roto y que la sociedad está muerta» (151).

La erosión de los valores clásicos -irreparable, pues la cultura, según Bell, posee una cualidad orgánica que impide que se la pueda crear artificialmente, por la fuerza de un fiat- se potencia, por lo demás, con la incapacidad de dar vida a nuevas tradiciones culturales y nuevas justificaciones que procuren sostén al conjunto de la sociedad. Los ritmos de creación cultural, pese a la permeabilidad de sus fenómenos, se desarrollan siempre con mayor lentitud que los procesos positivos y negativos de los otros órdenes. La legitimación se convierte, pues, en el problema central de una sociedad cuyas necesidades legitimatorias se han incrementado en la misma medida en que han desaparecido prácticamente los espacios exentos, sin que, por otra parte, las potencialidades de legitimación se hayan mantenido ni siquiera en los niveles tradicionales.

(8) Vid. al respecto H. Marcuse: "Ueber den affirmativen Charakter der Kultur", en Kultur und Gesellschaft, 1, Suhrkamp, Frankfurt a. M., 1965, págs. 56101; id., An Essay on Liberation, Beacon Press, Boston, 1969; id., Konterrevolution und Revolte, Suhrkamp, Frankfurt a. M. 1973, en especial el cap. 3: "Kunst und Revolution", págs. 95 ss. De Jürgen HabERmas vid. Legitimationsprobleme im Spätkapitalismus, Suhrkamp, Franfurt a. M., 1973, págs. 118 ss. (hay trad. castellana en Amorrortu, Buenos Aires, 1975, bajo el título de Problemas de legitimación en el capitalismo tardío); id., "Bewusstmachende oder rettende Kritik - Die Aktualität Walter Benjamins", en Kultur und Kritik, Suhrkamp, Frankfurt a. M., 1973, págs. 302-344. 
4. Tras haber dedicado sendos estudios a los aspectos tecno-económicos y culturales de la sociedad contemporánea ( $«$ El advenimiento de la sociedad postindustrial» $\mathrm{y}$ «Las contradicciones culturales del capitalismo»), Bell promete cerrar sus análisis con una obra centrada en lo que él llama también las contradicciones políticas de la sociedad actual. En ello es enteramente fiel a su esquema teórico. Sin embargo, la circunstancia de que una gran parte de su estudio sobre la problemática (o, mejor, lo problemático) de la cultura en la sociedad capitalista se haya de dedicar a examinar extensamente los problemas políticos fundamentales de tal sociedad atestigua la imposibilidad de llevar adelante sus disgregadores esquemas.

Pues la agudización de los problemas de legitimación tiene también lugar por una vía directamente política. De acuerdo —una vez más- con Jürgen Habermas, Bell cree poder constatar, como ya apuntamos, un desplazamiento del gobierno de la sociedad desde la economía (el mercado) hacia la esfera política (el Estado) paralelo a la debilitación de los vínculos entre economía y comportamiento social, lo que Bell denomina expresivamente, parafraseando una terminología económica, un incremento de la conducta social discrecional (49), la disyunción creciente entre la conducta y el locus social -in argumento muy similar, por lo demás, al de la sustitución de las desigualdades clasistas por formas de disparidad horizontal (Offe) o de relative deprivation (Runciman).

El caso es que, por un sinfín de circunstancias (de cuyo examen más detallado Bell, sintomáticamente, se exime), el Estado ha tenido que ir asumiendo un número cada vez mayor de funciones regulativas hasta convertirse en el principio básico de asignación de la sociedad (215). Este extremo es relevante en lo que atañe a la legitimación del orden político, pues mientras el mercado se legitimaba a sí mismo o, cuando menos, contribuía a evitar los problemas de legitimación en la medida en que acertaba a despolitizar la relación social constitutiva, el Estado -y más aún el Estado democrático burguéstiene que procurarse legitimidad para sus actos e intervenciones. Y ésta es una tarea tanto más difícil por cuanto mientras el mercado - un mecanismo de por sí difuso- dispersa las responsabilidades,

«en el caso de las decisiones públicas ajenas al mercado, la situación es en todo diferente. Las decisiones son visibles y se sabe a quién acusar» (188).

A esta circunstancia se suma otra no menos grave: mientras que todos conocen los límites de sus particulares economías, nadie conoce, ni siquiera aproximadamente, los límites de lo que el Estado puede ofrecer y, por consiguiente, de lo que se le puede exigir. Los problemas en este orden se agravan en virtud de una dialéctica, entrevista ya por Tocqueville, que hace que las expectativas derivadas del crecimiento se conviertan, en un primer paso, en pretensiones y, en un segundo momento, en derechos exigibles, dando 
origen a lo que Bell denomina revolution of rising entitlements. En este sentido, el crecimiento económico se muestra inequívocamente, frente al criterio generalizado, como un considerable factor de inestabilidad social, lo que supone un muy grave problema, puesto que, por encima de todo, el crecimiento mismo es un imperativo absoluto de la economía capitalista.

El Estado —en un análisis que Bell toma explícitamente de Jim O'Connor (9) y que suscribiría casi por completo si el marxista norteamericano postulara la extensión de la validez de sus reflexiones al conjunto de las sociedades industrializadas (219) - tiene, efectivamente, que procurar satisfacción simultánea a dos necesidades básicas: acumulación y legitimación. Para garantizar esta última, el Estado tiene que convertirse en Estado de bienestar, Estado social. Cuando ya no es posible mantener la ficción de la armonía de las realidades de la sociedad burguesa con su universalista ideología, cuando la apatía - y no la participación ciudadana - se ha convertido en una de las condiciones previas para el buen funcionamiento del mecanismo, sólo se puede recurrir a las prestaciones sociales como vía para asegurar la lealtad de las masas (10). Ahora bien, el creciente volumen de los gastos sociales puede llegar a afectar a la función de garantía de la acumulación: la única forma que tiene el Estado capitalista de procurarse los medios económicos para la ejecución y continua ampliación de su política social es la detracción fiscal, y ésta sólo puede llevarse a cabo mediante una reducción de las capacidades de acumulación de capital privado. El carácter contradictorio de estas dos funciones que el Estado ha de cumplir simultáneamente es lo que se entiende por la crisis fiscal, una forma de crisis que se superpone a la crisis de legitimación (y motivación) a que antes aludíamos. En este marco no es, pues, de extrañar el papel relevante que en el pensamiento político de Daniel Bell pasa a desempeñar la resucitada «sociología fiscal» (11). Una de las cuestiones básicas del orden político actual se contempla así en el hecho de que todos los grupos tratan de incrementar al máximo su partici-

(9) James O'Connor: The Fiscal Crisis of the State, St. Martin's Press, Nueva York, 1973 (hay. trad. castellana en Periferia, Buenos Aires, 1974, bajo el título Estado y capitalismo en la sociedad norteamericana).

(10) Vid. en torno al concepto de lealtad de masas Wolf-DIETER NarR y Claus OFFE: "Einleitung", en Narr-Offe (eds.): Wohlfahrtsstaat und Massenloyalität, Kiepenheuer \& Witsch, Colonia, 1975, págs. 7-46, esp. 27-37. Paralela a la sustitución de legitimidad por lealtad de masas es la utilización de "valor" en lugar de "sentido" para vincular y motivar a los ciudadanos. Sobre esta relación sustitutiva y sus implicaciones, vid. J. Habermas: Legitimationsprobleme..., op. cit., pág. 104.

(11) Cfr. los textos clásicos de la sociología fiscal en Rudolf Gocoschero y Joseph SCHUMPETER: Die Finanzkrise des Steuerstaates. Beiträgen zur politischen Oekonomie der Staatsfinanzen, herausgegeben von Rudolf Hickel, Suhrkamp, Frankfurt a. M., 1976. 
pación en las atenciones del Estado a costa de los demás grupos y, por tanto, de la sociedad en su conjunto (12).

Pero la sociología fiscal cumple en Bell una función de mayor alcance, proporcionando también un marco para la formulación de su concepto del Estado. Se le trata de entender no como un sector —el público-, sino como un presupuesto, como una unidad doméstica cuyos límites, por amplios, no hacen desaparecer en modo alguno esa condición cuasi-familiar de la polity. $\mathrm{Y}$ lo característico de un presupuesto es que por constitución resulta apto para satisfacer necesidades, no deseos; necesidades del conjunto de los integrantes de la unidad doméstica en cuestión - necesidades públicas, pues, en el caso del Estado-, pero nunca deseos (intereses) de esos agentes híbridos que han socavado la unidad del oikos público y que son los grupos.

Estas consideraciones dan pie a Bell para precisar en esos etéreos términos la contradicción básica del Estado social, un mecanismo que, creado en principio para la satisfacción de necesidades públicas, degenera hasta convertirse en el ruedo de pretensiones comunalizadas. Sin embargo $-y$ aquí se separan definitivamente los enfoques de Bell y Habermas-, la contradicción básica de la sociedad capitalista ( $\mathrm{y}$, por ende, del Estado) la sigue constituyendo lo que Habermas, en una terminología esotérica, califica de «producción socializada para fines no generalizables», esto es: el dilema marxista del carácter social de la producción de riqueza frente a las condiciones privadas de su apropiación. En este marco, en cuya discusión Bell no entra, las transformaciones del Estado liberal siguen la lógica y los intereses del orden capitalista burgués, sin que el Estado social llegue a suponer una contradicción en los términos que Bell sostiene.

$\mathrm{Y}$ es que los planteamientos de Bell en torno al Estado de la sociedad industrial se encuentran absolutamente condicionados por su creencia en el carácter coyuntural, no necesario, de la pareja liberalismo-capitalismo, liberalismo-sociedad burguesa. Sólo aceptando lo azaroso de su confluencia en la historia más reciente puede compartirse la pretensión de Bell de la restauración de una filosofía pública liberal como la solución para la crisis cultural que afecta a la sociedad llamada occidental. Pero la premisa es demasiado ambiciosa y son muchas todavía las circunstancias que hablan en su contra como para creerla firmemente establecida en las ricas y elegantes disgresiones de Las contradicciones culturales del capitalismo.

(12) Vid. acerca del papel de los grupos en el Estado social el importante estudio de Manuel García Prlayo: "Las organizaciones de intereses y la teoría constitucional", en Las transformaciones del Estado contemporáneo, Alianza Editorial, Madrid, 1977, págs. 108-135. 


\section{CRITICA DE LIBROS}

